\title{
Erratum to "Representing Error bars in within- subject designs in typical software packages"
}

\author{
Fearghal O'Brien a, Denis Cousineau ${ }^{\Xi}, \mathrm{b}$ \\ a School of psychology, Trinity College Dublin, Ireland \\ b École de psychologie, Université d'Ottawa, Canada
}

Abstract $=$ An error was present in the Matlab code used to standardize the data matrix. Here the instruction is corrected.

Keywords = Error bars, within-subject designs; Matlab

$\equiv$ denis.cousineau@uottawa.ca

\section{Introduction}

The method proposed in O'Brien and Cousineau (2014) is based on two transformations of the data set $\mathbf{X}$. In the paper, an error was present in the Matlab instructions to perform the second transformation. Here we report the correct instruction.

\section{Authors' notes and acknowledgments}

The authors would like to thank Stéphane Dufau for signaling the error and providing the corrected instruction.

\section{References}

O'Brien, F., \& Cousineau, D. (2014). Representing Error bars in within-subject designs in typical software packages. The Quantitative Methods for Psychology, $10,56-67$

\section{Appendix}

The erroneous instruction was

$Z=\left(\operatorname{sqrt}(J /(J-1)) \cdot *\left(Y^{\prime}-\operatorname{repmat}(\operatorname{mean}(Y), \operatorname{size}(Y, 1), 1)^{\prime}\right)^{\prime}\right.$

The corrected instruction is:

$\mathrm{Z}=\operatorname{sqrt}(\mathrm{J} /(\mathrm{J}-1)) . *\left(\mathrm{Y}^{\prime}-\operatorname{repmat}(\operatorname{mean}(\mathrm{Y}), \operatorname{size}(\mathrm{Y}, 1), 1)^{\prime}\right)^{\prime}+{ }^{\prime}(\operatorname{repmat}(\operatorname{mean}(\mathrm{Y})$, $\left.\operatorname{size}(Y, 1), 1)^{\prime}\right)$ ' ;

Also note that the .* operation is not necessary as well as the transpose. A simpler instruction is therefore:

$\mathrm{Z}=\operatorname{sqrt}(\mathrm{J} /(\mathrm{J}-1)) *(\mathrm{Y}-\operatorname{repmat}(\operatorname{mean}(\mathrm{Y}), \operatorname{size}(\mathrm{Y}, 1), 1))+\operatorname{repmat}(\operatorname{mean}(\mathrm{Y}), \operatorname{size}(\mathrm{Y}, 1), 1) ;$

\section{Citation}

O'Brien, F., \& Cousineau, D. (2015). Erratum to "Representing Error bars in within-subject designs in typical software packages". The Quantitative Methods for Psychology, 11 (2), 126-126. 